\title{
USABILIDADE E UX NO ATENDIMENTO DIGITAL AO CLIENTE DE ENERGIA ELÉTRICA
}

\section{USABILITY AND UX IN THE DIGITAL CUSTOMER SERVICE OF AN ELECTRIC UTILITY}

\author{
Giovanni Moura de Holanda ${ }^{1}$, M.Sc. \\ gholanda@fitec.org.br e http://orcid.org/0000-0001-5603-2675 \\ Cristina Yurika K. Obata Adorni ${ }^{1}$, Bach. \\ cadorni@fitec.org.br e http://orcid.org/0000-0001-8440-1896 \\ Luciana Allegretti de Andrade ${ }^{1}$, Bach. \\ lallegretti@,fitec.org.br e http://orcid.org/0000-0002-2785-0430 \\ Regiane Rezende ${ }^{1}$, M.Sc. \\ rrezende@fitec.org.br e http://orcid.org/0000-0001-6382-9586 \\ Katerinne Rose Costa Pinheiro ${ }^{2}$, Bach. \\ katerinne.pinheiro@equatorialenergia.com.br e http://orcid.org/0000-0003-2038-0170 \\ ${ }^{1}$ FITec - Inovações Tecnológicas, Campinas - SP, Brasil \\ ${ }^{2}$ Equatorial Energia, Brasília, Brasil

\begin{abstract}
experiência do usuário, usabilidade, transformação digital, chatbot
Neste artigo são apresentados resultados dos esforços de pesquisa e desenvolvimento de um projeto de transformação digital que busca melhorar a experiência do usuário (UX) em jornadas de serviços baseadas em atendimento via chatbot. Esses esforços reúnem princípios e métodos inovadores em usabilidade e UX para aplicá-los na estruturação do fluxo de conversação de dois serviços de atendimento digital: um para solicitações de novas ligações de energia elétrica e outro para solicitação de reativação de energia. A interação com quem solicita o serviço será realizada via WhatsApp pela assistente virtual personificada "Clara". Trata-se de serviços que requerem sequências complexas de informações para efeito do cadastro de cliente e do local que receberá a energia. Tais características impõem desafios de usabilidade para que a troca de informação com a assistente virtual seja efetiva, rápida e minimamente dificultosa, tendo em vista o contexto sociocultural e digital das pessoas que interagirão com a Clara, as regras de negócio e o legado tecnológico da concessionária de distribuição de energia, bem como as características da interface de interação.
\end{abstract}

user experience, usability, digital transformation, chatbot

This paper presents the results of the research and development efforts of a digital transformation project that aims at improving the user experience (UX) during interactions with a chatbot. The efforts bring together innovative principles and methods in usability and UX to apply them in the structuring of the conversation flow of two digital attendance services: one for requests for new electrical power connections and another for requesting electrical power reactivation. The interaction with those requesting the service will be carried out via WhatsApp by the personified virtual assistant "Clara". These are services that require complex sequences of information for the purpose of registering the customer and the location that will receive the energy. Such characteristics pose usability challenges so that the exchange of information with the virtual assistant can be effective, fast, and minimally difficult, considering the sociocultural and digital context of the people who will interact with Clara, the business rules and the technological legacy of the energy distribution utility, as well as the digital interface characteristics. 


\section{Introdução}

De modo geral, a jornada de uma pessoa em aplicações e serviços interativos humano-computador é diretamente influenciada por aspectos de usabilidade, tipos de linguagem e estruturas narrativas usados em um processo de atendimento que cognitivamente é recente para as tratativas interrelacionais do ser humano. Neste artigo, são apresentados resultados de estudos e design de soluções que buscam melhorar a experiência do usuário (UX) em jornadas desse tipo de serviços, baseados em atendimento digital e automatizado em que as pessoas interagem com uma assistente virtual para ter suas necessidades atendidas. Tais resultados fazem parte de um projeto de transformação digital que está sendo conduzido na Equatorial Energia, uma concessionária de distribuição de energia elétrica, dentro do escopo de pesquisa e desenvolvimento da ANEEL (Agência Nacional de Energia Elétrica).

O foco deste artigo recai nos princípios e métodos inovadores em usabilidade e UX que foram aplicados na estruturação do fluxo de conversação de dois serviços de atendimento dessa concessionária, os quais são providos por uma assistente virtual via WhatsApp. Esses serviços destinam-se a atender quem solicita uma ligação nova de energia elétrica ou a quem deseja reativar uma conexão que estava desligada. Fazem parte do portfólio de serviços atendidos pela Clara, a assistente virtual personificada que tem seu fluxo de diálogo estruturado com recursos de Processamento de Linguagem Natural (NLP, na sigla em inglês) da plataforma Watson IBM.

Entre os desafios encontrados para a proposição de soluções estão a necessidade de considerar o contexto sociocultural e as condições de uso das tecnologias digitais das pessoas que fazem uso desses serviços, o legado tecnológico da distribuidora de energia, a regulação do setor elétrico e as características do canal em que o serviço é ofertado. Para se ter uma ideia desses desafios, trata-se de serviços complexos, que envolvem muita interação com a pessoa solicitante para fazer um cadastro de cliente e de unidade consumidora - $\mathrm{O}$ local, residência, em que será feita a ligação ou reativação de energia- observando todas as exigências regulatórias e de negócio, e as limitações de interface e do canal de comunicação. O que já é relativamente complexo em um atendimento presencial, agora sendo feito integralmente no WhatsApp, em uma interação de ponta a ponta com uma assistente virtual.

A partir da definição dos princípios e métodos, buscou-se conceber soluções que contribuam para elevar o nível da experiência percebida pelos clientes da concessionária. Para refletir o contexto desses clientes, o design de diálogo foi baseado em estudos da persona identificada como chave para a concepção de novas soluções, procurando proporcionar empatia com seu perfil e moldando-se às suas características sociolinguísticas, além de respeitar os atributos gerais da própria personalidade da Clara. Aqui consideramos que as características associadas à imagem da assistente virtual guardam propriedades que atribuem uma "personalidade" a ela, entendida no conceito do senso comum e não como definição científica. Tais características estão relacionadas à forma física, faixa etária, gênero, tipo de compleição, vestuário etc.

Além dos desafios de usabilidade e UX, este projeto de transformação digital impõe-se a condição de prover soluções integralmente digitais, sem a necessidade de atividades complementares da retaguarda administrativa (back-office) da concessionária. Os benefícios advindos ao se buscar alcançar tal condição decorrem, por um lado, da necessidade de repensar e simplificar o formato de interações para quem solicita a ligação nova, sem ferir as regras de negócio; e, por outro lado, de um natural desembaraço (ou diminuição de esforço) dos processos internos administrativos.

O artigo está estruturado em mais três seções. A Seção 2 apresenta alguns conceitos básicos sobre usabilidade e UX para possibilitar um entendimento comum acerca da abordagem que está sendo proposta. Com base na literatura e em normas recomendativas sobre o tema, destaca-se a importância da usabilidade e da multimodalidade como fatores para promover níveis mais satisfatórios de UX em jornadas interativas. 
A Seção 3 traz alguns resultados de como os princípios de design centrado no ser humano, apontados no capítulo conceitual, os estudos de empatia em torno da persona identificada como chave para o projeto, bem como sprints de design foram formatados em soluções de usabilidade para a interação do cliente com a Clara, durante as jornadas de solicitação via WhatsApp. São apresentadas as principais linhas de design que foram concebidas para trabalhar a usabilidade, e por extensão a experiência do usuário, nas interações do trâmite de solicitação de uma ligação nova ou de uma reativação de energia.

Almejando tecer as considerações finais sobre os resultados alcançados até o estágio atual de execução do projeto, a Seção 4 também aponta os próximos passos previstos e as linhas de pesquisa que podem ser aprofundadas em desdobramentos futuros de desenvolvimento.

\section{Conceitos e princípios: focalizando usabilidade e UX}

Sistemas interativos, como serviços com interação humano-máquina através de agentes virtuais, têm despertado o interesse de acadêmicos e engenheiros projetistas desde longa data. No início dos anos 90, Nielsen e Molich (1990) já traçavam diretrizes sobre a usabilidade interfaces e Norman (1994) investigava sobre esse conceito até então mais próximo dos cenários de ficção científica, refletindo sobre como agentes inteligentes interagiriam com pessoas e qual seriam as formas mais adequadas para tal relação. Décadas depois, e com todo o avanço dos sistemas inteligentes e de sua participação cada vez maior no cotidiano relacional das pessoas, muitos aspectos relacionados a essa interação ainda são desconhecidos e eventualmente inimaginados. Reflexões sobre a interação humano-computador (HCI, na sigla em inglês) e o papel dos chatbots, nesse contexto são apresentadas, por exemplo, em (FØLSTAD; BRANDTZÆG, 2017; BRANDTZÆG; FØLSTAD, 2018; HILL, FORD, FARRERAS, 2015).

Com o intuito de criar uma base comum de entendimento sobre os impactos causados pelos sistemas e serviços interativos na experiência do usuário, adotamos aqui o entendimento atribuído pela ABNT NBR ISO 9241-210 ao termo usabilidade, ou seja, "medida em que um sistema, produto ou serviço pode ser usado por usuários específicos para se atingir objetivos específicos com eficácia, eficiência e satisfação, em um determinado contexto de uso".

Por sua vez, a experiência do usuário é definida por essa mesma norma como "percepções e respostas das pessoas, resultantes do uso e/ou uso antecipado de um produto, sistema ou serviço". A Nota 1 referente a esse termo, acrescenta que: "experiência do usuário inclui todas as emoções, crenças, preferências, percepções, respostas físicas e psicológicas, comportamentos e realizações do usuário que ocorrem antes, durante e depois do uso". Dessa forma, os termos usabilidade e UX inter-relacionam-se, uma vez que critérios de usabilidade podem servir para avaliar aspectos relacionados à UX, como destaca ainda a Norma (ASSOCIAÇÃO BRASILEIRA DE NORMAS TÉCNICAS, 2011).

Como pano de fundo para definição do termos-chave que pontuam este artigo, destacamos o conceito da abordagem de projeto centrado no ser humano e o de design centrado no usuário, que estabelecem relação direta com os princípios e métodos de usabilidade e UX. Apesar de compartilharem a mesma essência, apresentam algumas especificidades de forma que acompanham o próprio amadurecimento do tema que, no contexto do que pretendemos expor a seguir, podem ser tratados como equivalentes.

Recorrendo mais uma vez à ABNT NBR ISO 9241-210, a abordagem de projeto centrado no ser humano é voltada a sistemas interativos que por meio técnicas de usabilidade e fatores humanos e de ergonomia almejam tornar os sistemas utilizáveis e úteis, no atendimento às necessidades do usuário.

Consequentemente, tal abordagem contribui para elevar o nível de vários aspectos relacionados à UX, por exemplo, eficácia e eficiência, acessibilidade e sustentabilidade, índice de satisfação do usuário e bem-estar do ser humano, sem mencionar aspectos de natureza mais técnica e operacional, como segurança e no desempenho. 
Em um dos trabalhos seminais sobre o tema, ainda com a terminologia de design centrado no usuário (Usercentered Design - UCD), Vredenburg et al. (2002) definiram o UCD como o envolvimento ativo de usuários para uma compreensão clara de requisitos de usuários, design e avaliação iterativos, e uma abordagem multidisciplinar. Com o foco voltado a projetos de inovação que implicam em pessoas utilizando seus resultados, Dopp et al. (2018) apresentam um glossário de estratégias para UCD, considerando que é um campo de investigação com terminologia e abordagens variadas.

Já em um contexto mais recente, a Norma ABNT NBR ISO 9241-210 apresenta um arcabouço conceitual voltado ao design centrado no ser humano, que inclui os elementos presentes na definição acima. Os princípios que norteiam o arcabouço da Norma apontam que o projeto deve:

- Ser baseado no entendimento explícito dos usuários, incluindo tarefas e ambientes, e que esses devem ser envolvidos em todo o projeto.

- Apoiar-se em avaliações centradas no usuário com o intuito de aprimoramento iterativo, abordando toda a experiência do usuário e tendo claro que as soluções iniciais raramente satisfazem o conjunto de necessidades e preferências do usuário.

- Ser conduzido por uma equipe com competências e perspectivas multidisciplinares.

Outro desdobramento importante e relacionado diretamente à experiência do usuário refere-se a quais funções serão desempenhadas pela tecnologia. Essa é uma questão que deve ser considerada nas decisões de projeto, as quais devem considerar capacidades e limitações do ser humano quanto ao uso e apropriação da tecnologia.

Isso reforça o fato de que o design de recursos interativos com impactos na UX também deve considerar o contexto multicultural dos usuários que serão alcançados pelo serviço ou produto a ser desenvolvido - cf. (HE, 2020; BEKELE, GROHER, SAMETINGER, 2019). De um modo geral, as organizações têm buscado desenvolver uma cultura de UX, capacitando designers e criando métodos de design e estratégias de pesquisa relacionadas a HCI e UX (MacDonald, 2019).

Em termos das melhores práticas de projetos centrados no usuário, Gualtieri (2009), por exemplo, apresenta uma visão da Forrester Research em que os desenvolvedores devem proporcionar experiências que sejam úteis, utilizáveis e desejáveis. Como útil, está a experiência em que o cliente pode alcançar seus objetivos; sendo utilizável, ele pode facilmente realizar tarefas; e é desejável quando o cliente pode apreciar a experiência. Para tanto recomenda que se deve ouvir as necessidades do usuário, observando-o em seu contexto; criar personas representantes do segmento da população que se pretende atingir; criar empatia com elas, tornando-se o usuário; e introduzir UX design em todo o ciclo de desenvolvimento da solução. Além disso, Gualtieri (2009) aponta práticas como, entre outras:

- Desenhar para mudanças, considerando aspectos culturais, realidade econômica e tecnologia;

- Iniciar com protótipos de baixa fidelidade, considerando todos os aspectos da UX (projeto visual e interativo, bem como testes e validação da usabilidade), entre outras práticas, como testar continuamente considerando que as expectativas do usuário mudam com o tempo.

Com o olhar direcionado para o design de UX, Morville (2004) desenvolveu um diagrama para representar as facetas da experiência do usuário, baseando-se na metáfora da colmeia de abelhas e com a intenção de proporcionar uma base de entendimento que fosse além do que caracteriza a usabilidade. Entre as facetas que acrescenta estão: ser valioso, encontrável, acessível e credível (ou crível). O fato de ser encontrável implica em desenhos que possibilitem ao usuário encontrar o que necessita; ser acessível favorece a inclusão de pessoas com deficiências; ser valioso entrega valor para os stakeholders e aumenta a satisfação do usuário; e 
ser crível significa incluir elementos de design que levam os usuários a sentirem confiança e acreditarem no que está sendo dito e apresentado.

Outro reforço de princípios de design é encontrado em (MAHLKE, 2007), que apresenta um framework de pesquisa conceituando a UX como a combinação de percepções de qualidade instrumental e não instrumental, além de reações emocionais do usuário. Entre os resultados obtidos com os estudos conduzidos pelo autor está o de que a experiência do usuário, do ponto de vista da interação com o serviço ou tecnologia, é apenas um dos aspectos da experiência completa do cliente, e ao se desenhar soluções de interação, as necessidades cognitivas e emocionais do usuário devem ser consideradas. Springett e French (2007) também agregam seus pontos de vista, assinalando que a semiótica ajuda a entender como os usuários desconstrói e interpreta UX.

Antes disso, Lemke (2002), com o conceito de hipermodalidade, já inter-relacionava elementos de semiótica - palavras, imagens e sons - na construção de significados no ambiente hipermídia, com o objetivo de tornar a comunicação mais efetiva. Para Lemke, texto e imagem contextualizam-se mutuamente e nunca contam a mesma história, forçando-nos a análises mais críticas do que cada modalidade poderia levar isoladamente.

Esses conceitos e princípios aqui sumariamente constituem o arcabouço que serviu de base para o design de elementos de usabilidade e para o próprio desenvolvimento da estrutura lógica e do fluxo conversacional do serviço de Ligação Nova, o qual vem sendo levado a cabo e a termo neste projeto.

\section{Agilizando e simplificando o fluxo conversacional}

A solicitação de uma ligação nova ou de reativação de energia são serviços de alta complexidade em termos de interação com quem faz o pedido, uma vez que é necessário levantar várias informações cadastrais e técnicas para atender às regras de negócio e operacionalizar a ligação física propriamente dita.

Com base no exposto no capítulo anterior e balizando-nos também em sprints de design acerca das dores e necessidades da persona identificada como chave para o projeto, percebeu-se a necessidade de se traduzir os aspectos técnicos requeridos pela regra de negócio para uma linguagem mais acessível. O perfil da persona reflete uma mulher com mais de 50 anos de idade, muito ocupada com o trabalho diário e os problemas da família, não tem wi-fi em casa e usa pouco a internet de forma autônoma, sem ajuda de alguém, apenas o WhatsApp para conversar com o grupo familiar. Esse perfil foi trazido para as oficinas iniciais de design pela concessionária, como sendo o que, pela experiência prévia de interações com clientes, enseja desafios significantes para atendimentos digitais com as caracteristicas deste projeto.

Nos estudos e prototipagem inicial, percebeu-se a oportunidade de aumentar a eficiência da comunicação com o uso de figurinhas (por exemplo, os emojis) e cores para destacar as mensagens e agregar informação visual. Narrativas no formato de histórias em quadrinhos (HQ) tenderam a criar empatia e simplificar a comunicação de temas menos palatáveis, como recomendações técnicas. Além disso, considerou-se que para conferir características humanas ao diálogo da Clara, aspecto que potencializa a empatia das pessoas com o chatbot, seria necessário incluir fatores de contexto, reações que reflitam um certo pathos frente a situações de dificuldade ou de sucesso, e alguma capacidade de raciocínio durante a conversação e solicitação de informações do cliente. Esses são alguns recursos viabilizados pela inteligência artificial e que podem minimizar os esforços de interação entre humanos e chatbots (HOLANDA; REZENDE; SOUZA, 2021)

Tendo esses aspectos como desafios a serem superados, e considerando os pontos de dificuldade já detectados pela equipe de atendimento ao cliente da concessionária no tocante a esses dois serviços, destacamos três linhas de design a serem conduzidas neste projeto com o intuito de melhorar a usabilidade e, por extensão, a experiência do usuário que solicitará uma ligação nova ou reativação de energia pela Clara via WhatsApp. Essas linhas, detalhadas e embasadas a seguir, atuam nas etapas necessárias ao fluxo de 
negócio e fazem parte do trâmite de solicitação para cadastro de clientes e da unidade consumidora que se pretende criar.

- Otimização da sequência de etapas do fluxo de conversão

Um dos pontos já levantados pelo atendimento ao cliente é a complexidade da solicitação de uma ligação nova, com muitas etapas requerendo interações complexas para fornecimento das informações necessárias ao cadastro e à caracterização técnica da unidade consumidora de energia. Diante disso e das sinalizações captadas nas oficinas de prototipagem, observou-se a necessidade de ordenar as etapas de interação com o cliente para não apenas contextualizar o usuário na sua jornada de solicitação como para coadunar-se com o nível de letramento digital e os significados historicamente construídos pelos usuários que se ajustam na persona escolhida como chave para este projeto. Assim, buscou-se trabalhar com construções discursivas - no sentido encontrado nos estudos de Michel Foucault, $c f$. (2002) - para moldar regularmente o diálogo cliente-chatbot, de forma que fosse permitido ao interlocutor humano produzir sentido e apropriar-se do discurso. Quando as particularidades da linguagem humana estão presentes numa comunicação humanochatbot, observa-se diferenças significativas na qualidade da interação (HILL; FORD; FARRERAS, 2015). Além de endereçar a lógica do diálogo e apresentar utilidade quanto à resolução do problema do usuário, retendo sua atenção para seguimento da jornada, práticas de UX design - ver, por exemplo (GUALTIERI, 2009) - apontam que a solução encontrada deve permitir que as tarefas sejam realizadas com o mínimo de esforço. Isso requer que a jornada de interação seja ordenada e simplificada, trabalhando a expectativa do usuário com um menor número de etapas e sem o fornecimento de informações desnecessárias ou duplicadas.

\section{- Sinopse da jornada de solicitação com recursos multilinguagem}

Além de prover soluções centradas no ser humano, com jornadas descomplicadas e atraentes que mantenham a atenção do usuário, recursos multilinguagem - que combinem texto, imagem e áudio facilitam o uso e contribuem para aclimatar o usuário, sobrepujando barreiras de afinidade tecnológica e moldando estruturas narrativas mais próximas da características linguísticas e socioculturais do público-alvo (HOLANDA; REZENDE; SOUZA, 2021). As novas tecnologias digitais possibilitam criar novos espaços para práticas letradas diversas, inclusive com a integração de múltiplas semioses - cf. (BRAGA, 2010). Com a hipermídia, as interações entre palavras, imagens e sons contribuem para a construção de significados (LEMKE, 2002) e a adoção de multilinguagem facilita o acesso e a fruição do conteúdo ofertado pelas mídias digitais - ver (PARK, HUMPHRY, 2019; ROJO, MOURA, 2019; BRAGA, 2015). A sinopse da jornada tem como objetivo lançar mão do potencial inclusivo da combinação de linguagens e contextualizar o usuário sobre as várias etapas que compõem fluxo de solicitação de um ligação nova.

\section{- Simplificação e "ludicização" do processo de declaração de carga}

O processo de declaração de carga, como detalhado a seguir, é um dos mais complexos da solicitação de uma ligação nova e foi claramente identificado nas oficinas de entendimento da persona como o que mais impõe dificuldades ao solicitante. Mesmo com as limitações exigidas pelo processo de adaptação de uma interação humano-computador, como redução de vocabulário e mensagens curtas, os usuários têm demonstrado disposição ao diálogo com os chatbots inteligentes (HILL; FORD; FARRERAS, 2015). A combinação de linguagens e a redução de informações tem potencial para simplificar esse processo e contribuir com o engajamento do usuário. Da mesma forma, recursos para proporcionar experiências mais lúdicas têm sido introduzidos para aumentar empatia (CAÇADOR; GANCHO; GOUVEIA, 2020). Adicionalmente à funcionalidade e à construção do discurso adequado, aspectos antropomórficos têm sido considerados no desenho dos agentes inteligentes e na curadoria de conteúdo. Observa-se um impacto significativo das características antropomórficas na aceitação do usuário; entretanto, a componente "utilidade" exerce um papel mais relevante do que a percepção hedônica e lúdica na composição da UX (RIETZ; BENKE; MAEDCHE, 2019). 
Em todas essas linhas, o design de diálogo foi baseado nas características e "dores" da persona-chave, procurando empatia com seu perfil e moldando-se às suas características sociolinguísticas, além de respeitar as características gerais de personalidade da Clara. Foi considerado o nível de letramento digital associado à persona-chave como fator importante para o uso do canal WhatsApp, o quanto a pessoa precisaria de ajuda para lidar com as mídias digitais, o grau de complexidade das informações técnicas sobre o consumo de energia que a residência a ser conectada terá, assim como os recursos de internet e do próprio aparelho para interação e fruição das informações (smartphone).

Por razões de espaço textual é à guisa de concisão, o presente artigo centra o foco no terceiro item, relativo ao processo de declaração de carga. Contudo, é apresentada uma breve descrição das duas outras linhas de design.

\subsection{Otimização da sequência de etapas do fluxo de conversação}

$\mathrm{Na}$ ordenação das etapas necessárias ao fluxo de negócio, buscou-se priorizar as que representassem uma condição de saída do canal, para evitar que a pessoa que solicita avance na jornada sem ter todas as condições requeridas. Com isso espera-se reduzir impactos negativos na UX, como irritabilidade pelo tempo dedicado sem conseguir êxito. Espera-se também capacitar clientes fornecendo-lhe informações básicas para que possam reunir os elementos necessários à jornada e trabalhar suas expectativas quanto a todas as etapas de interações que terá com a assistente virtual.

Tendo essa intenção como meta, as condições elegíveis para fazer a solicitação pelo canal WhatsApp são levantadas logo nas etapas iniciais da jornada. E logo após as boas-vindas, é apresentada uma sinopse da jornada que a pessoa solicitante terá pela frente. A própria sinopse esclarece mais sobre outras condições necessárias para seguir a jornada.

Ao chegar na etapa mais complexa, do ponto de vista de interação para coleta de dados, como o cadastro de cliente e o endereço da Unidade Consumidora (UC), a pessoa já passou por condições que poderiam resultar no encaminhamento para outros canais, aumentando assim as chances de conclusão exitosa da solicitação. Essa solicitação de dados cadastrais é preferencialmente realizada por leitura automática (OCR) do documento de identificação, e o endereço da UC pode ser obtido via compartilhamento de localização do próprio WhatsApp, recursos que buscam agilizar o processo e melhorar a usabilidade.

A possibilidade de disponibilização da localização pelo WhatsApp, quando consentida por quem está fazendo a solicitação, também contribui diretamente para a UX, reduzindo vários passos no processo de interação para coleta do endereço da UC (ver Figura 1a). Contribuição semelhante pode ser alcançada com o uso de ícones ilustrativos, como os emojis e imagens ilustrativas (ver Figura 1b). A combinação de texto e imagens - como mapas, desenhos e ícones ilustrativos que aparecem nos trechos de diálogo ilustrados na Figura 1 - avança para uma condição multilinguagem, que contribui para a simplificação do processo, para a usabilidade e o uso mais efetivo do canal de comunicação. 


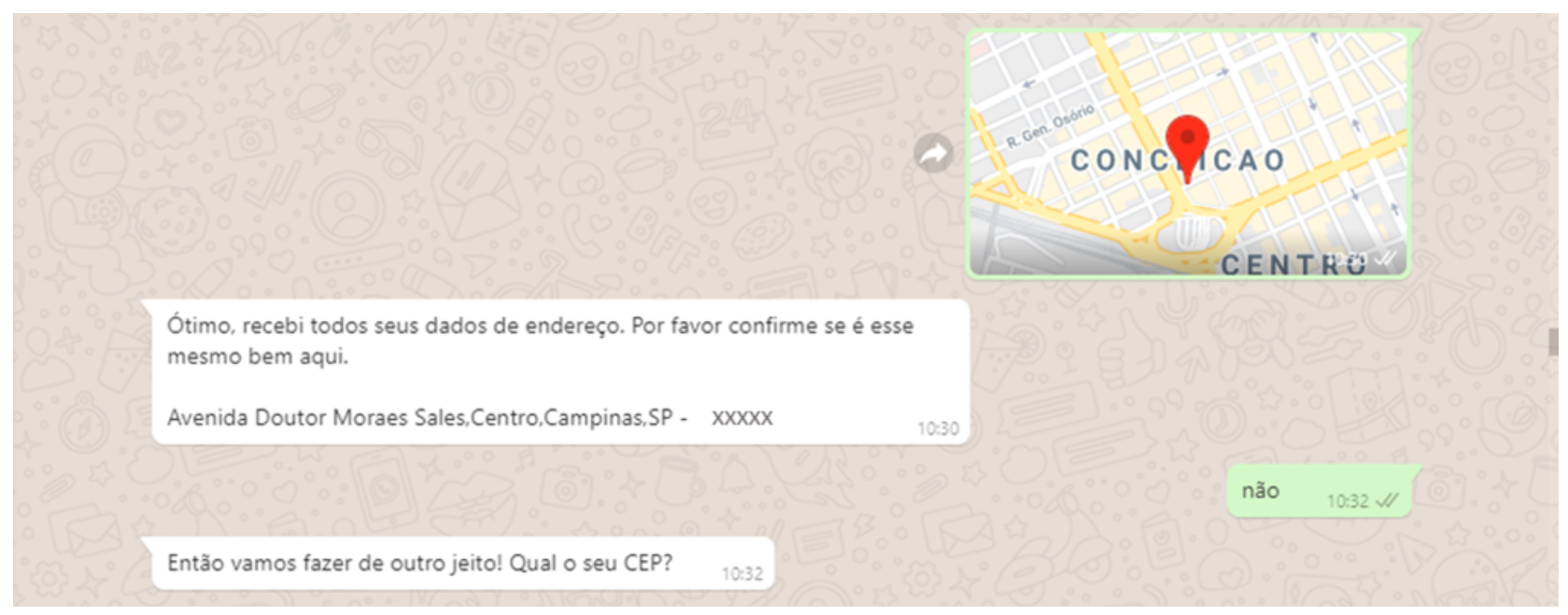

(a)

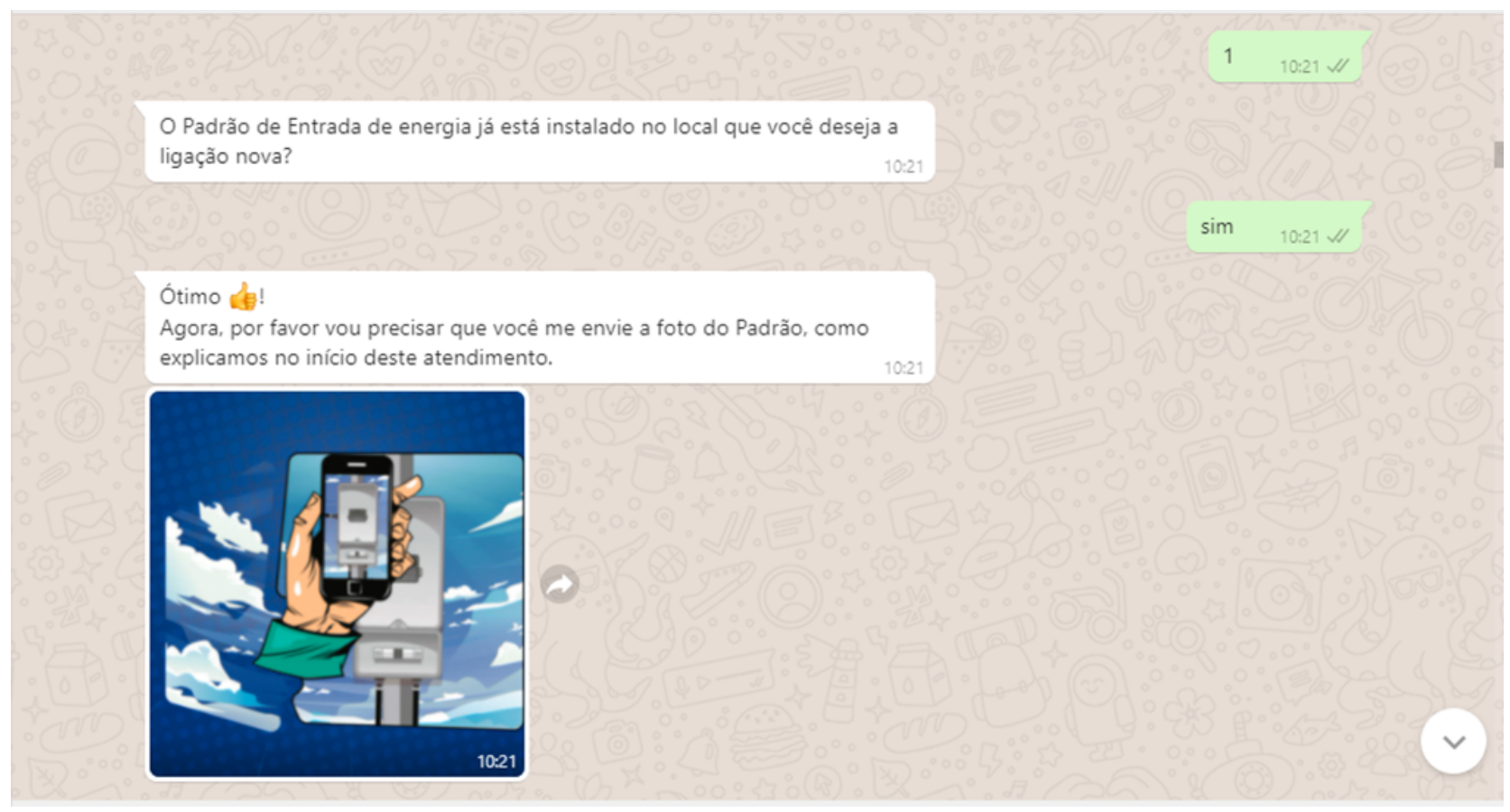

(b)

Figura 1 - Estudos do uso de recursos para melhorar UX Fonte: Elaborada pelos autores

Outro ponto da jornada que apresenta complexidade de interação é o de classificação da UC, conforme as regras de negócio da empresa. Essa etapa pode apresentar-se como um dificultador na interação entre a pessoa e a assistente virtual Clara. Para tanto buscou-se simplificar o fluxo, resumindo o questionário de classificação por associações lógicas. Dessa forma é possível resumir a quantidade de perguntas, mantendose praticamente a quantidade de informação obtida por canais já consolidados, como o atendimento presencial e a web. 


\subsection{Sinopse da jornada de solicitação com recursos multilinguagem}

Como mencionado anteriormente, foi pensando em apresentar de uma forma simples, objetiva e, de certa forma, lúdica, um resumo da jornada de quem solicita uma ligação nova ou reativação de energia pelo canal WhatsApp. O intuito desse recurso é duplo, tanto de capacitar a pessoa, fornecendo-lhe informações básicas sobre as condições para se usar aquele canal e os documentos que ela deve ter em mãos para prosseguir a jornada; quanto trabalhar transparentemente a sua expectativa quanto à jornada, fazendo uma prévia das principais etapas de interação com a Clara que ela terá pela frente.

Duas alternativas foram concebidas para apresentar essa sinopse: uma HQ (História em Quadrinhos), que apresentou bom potencial de comunicação na prototipagem, e uma animação baseada na própria HQ. Nas duas alternativas, buscou-se uma linguagem simples e lúdica, em narrativa protagonizada pela Clara e que agregasse na linha da multilinguagem, de modo a tornar a comunicação mais atrativa e principalmente efetiva. Ao mesmo tempo, considerou-se as limitações técnicas do canal em termos do tempo para carregar o arquivo de vídeo e as limitações de banda e de aparelho celular que normalmente possuem as pessoas com o perfil da persona em destaque neste estudo.

Alguns quadros da HQ e da própria "Sinopse da Jornada" do serviço Ligação Nova são apresentados na Figura 2, com a finalidade de ilustrar os recursos multilinguagem utilizados. No caso do vídeo, há também a voz da Clara narrando os textos que aparecem nos balões de diálogo, além de uma trilha musical de fundo. A jornada de um pedido para reativação de energia é similar. Os vídeos, com duração de 1 minuto e trinta segundos, contam com a narração das informações na voz da Clara, compondo um conteúdo multilinguagem, com texto, imagens, animação e áudio (trilha sonora e voz da Clara). Eles resumem as principais etapas da jornada, apresentado o passo a passo, as informações que serão solicitadas, como fotos de documentos pessoais, selfie da solicitante para prova de vida, orientação para captura de foto do padrão de entrada (descrito a seguir) que já deve estar instalado, compartilhamento da localização da residência pelo WhatsApp, prazos de atendimento etc.
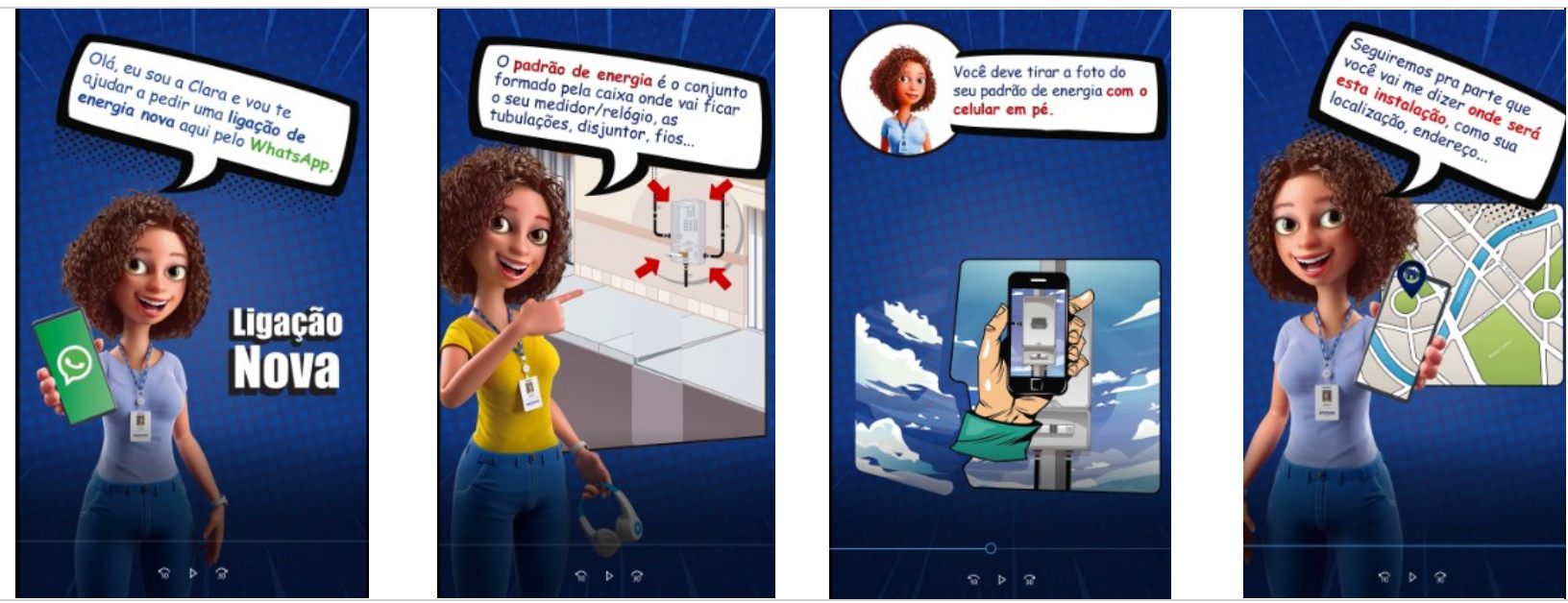

Figura 2 - Estudos do uso de recursos para melhorar a UX Fonte: Elaborada pelos autores

O terceiro quadro da Figura 2, da esquerda para a direita, corresponde a uma das instruções para captura de imagem (foto) do padrão de energia (o conjunto formado pela caixa onde fica o relógio medidor de consumo, as tubulações, fios, disjuntor...) existente no local onde será feita a ligação. Com base nessa foto, um modelo de aprendizado de máquina profundo (deep learning) foi desenvolvido para identificar a existência desse padrão e de algumas de suas características elétricas, contribuindo assim para aumentar a eficiência da equipe técnica da concessionária, uma vez que fornece informações para agilizar suas atividades em campo (FINARDI; HOLANDA; ADORNI; NADER; PINHEIRO, 2021). Nesse caso, o recurso de inteligência 
artificial contribui para o aumento da UX do cliente interno, associada ao consumo de informações necessárias à instalação de uma ligação nova ou reativação de energia em uma residência. O detalhamento sobre os esforços de P\&D para viabilização desse recurso de aprendizado de máquina foge ao escopo deste artigo.

\subsection{Simplificação e "ludicização" do processo de declaração de carga}

A previsão de consumo de energia e algumas características técnicas relativas à carga associada a esse consumo são necessárias para as providências da equipe de operações da concessionária de distribuição de energia, e fazem parte dos procedimentos da solicitação de uma ligação nova ou de reativação de energia. Atualmente, no atendimento presencial ou pela web, esse procedimento é baseado num longo e exaustivo questionário, com vários itens a serem preenchidos por quem solicita, o que, além de gerar uma certa dificuldade de entendimento para a pessoa, assume desafios ainda maiores quando se trata da interação pelo canal WhatsApp.

Uma solução proposta para simplificar o processo e melhorar a usabilidade é baseada na apresentação de cinco cenários de carga (denominados simplificadamente de opções) para que a solicitante selecione o que mais se aproxima de sua condição. As opções representam cenários de carga crescentes em termos de volume, desde uma situação de consumo muito baixo até um cenário de alto consumo, no limiar da classificação do Grupo B (que é uma classificação utilizada pelo setor elétrico para locais com carga de até $75 \mathrm{~kW}$ ). Cada opção corresponde a uma relação de possíveis itens de consumo de energia, como eletrodomésticos, equipamentos, chuveiros e lâmpadas. Os itens são apresentados em ícones com a respectiva descrição textual, conforme ilustrado na Figura 3 para a Opção 4, que representa o cenário de maior consumo dentre as opções apresentadas à pessoa solicitante.

Os cenários foram definidos em conjunto com a equipe da concessionária, reunindo um grupo multidisciplinar com representantes das áreas operacional e de marketing, buscando um equilíbrio entre simplificar o processo e obter informações básicas necessárias, se possível com precisão maior à que é obtida hoje. As ilustrações que apresentam os cenários a quem solicita foram preparadas com ênfase no uso semiótico de ícones para representar os itens de consumo e na utilização de cores para diferenciar os cenários informativos, almejando tornar mais lúdica e objetiva uma atividade relativamente complexa.

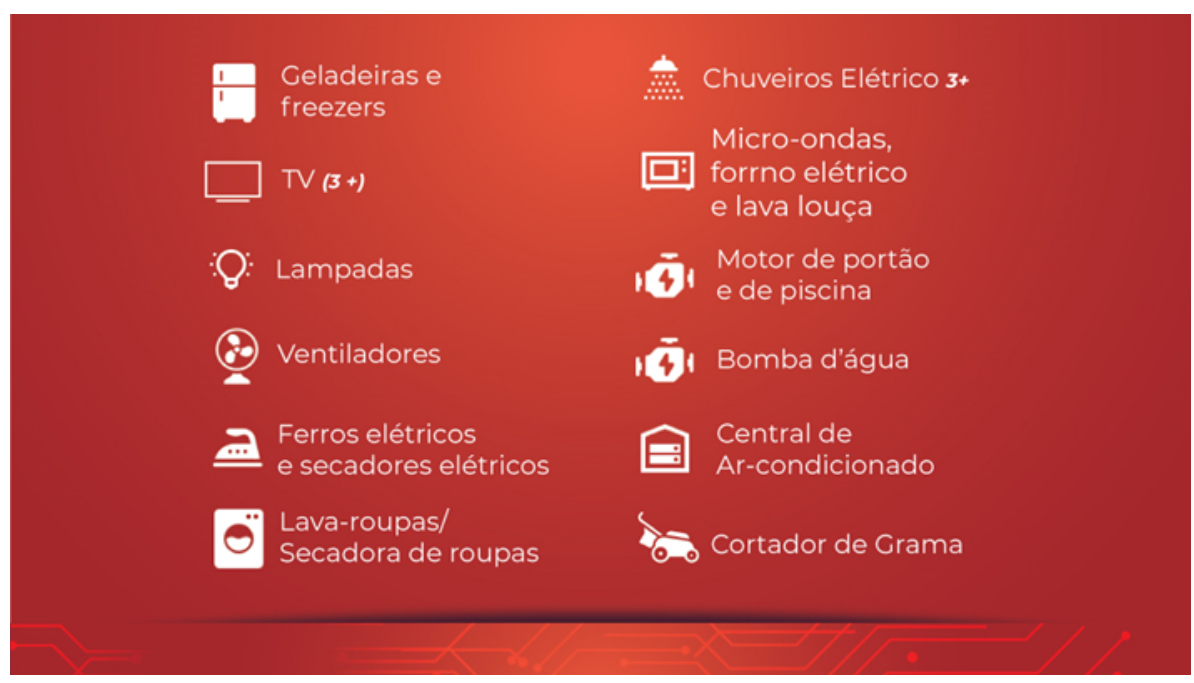

Figura 3 - Exemplo de itens (Opção 4) que compõem os cenários de carga Fonte: Elaborada pelos autores 
A ideia é apresentar à solicitante (na tela do WhatsApp) um card com as cinco opções para que ela faça a sua escolha a partir de uma única tela (ver Figura 4), quando a Clara solicita que se identifique a opção mais aproximada do tipo de consumo que a residência terá. Para a efetiva fruição das informações contidas nessa tela sinóptica, conta-se com as habilidades já adquiridas pela grande maioria das pessoas que lidam com os recursos tecnológicos e midiáticos que fazem parte do cotidiano da sociedade informacional que, nos moldes descritos por Castells (2017), caracterizam a era atual alcançada pelo processo civilizatório da humanidade.

Entre essas habilidades está a percepção intuitiva de interação com a tela física do smartphone, em que os movimentos dos dedos fazem o efeito de zoom out e zoom in, permitindo um encontro natural com a capacidade sensorial e cognitiva de quem interage com as mídias digitais. De certa forma, essa tendência se deve ao fato de que a cultura digital vem sendo semeada e fortificada por processos contínuos de produção, distribuição e consumo comunicacionais, a qual Lúcia Santaella (2003) denomina de cultura das mídias. Por essa perspectiva, é plausível considerar que, mesmo havendo a orientação "ampliar a imagem" no próprio card, tal recurso de usabilidade comporta-se mais como instrução de reforço, uma vez que a "mágica" da tela se ampliando está sendo gradualmente incorporada aos hábitos dos que "navegam" através das interfaces digitais.

As opções ilustradas pelos cards cobrem um leque de cenários de carga que vão desde um consumo muito baixo e sem a presença de cargas perturbadores ${ }^{1}$ (Opção 1) até um cenário de alto consumo com a presença de cargas perturbadoras (Opção 4). A Opção 5 apresenta um cenário particular, de consumo moderado, mas no limiar da classificação para padrão de entrada monofásico, e com a presença de pelo menos um elemento de carga perturbadora. Em síntese, esses cenários representam:

- Cenário 1: Grupo B monofásico $<50 \mathrm{~kW}$,

- Cenário 2: Grupo B monofásico $<50 \mathrm{~kW}$,

- Cenário 3: Grupo B trifásico $<50 \mathrm{~kW}$,

- Cenário 4: Grupo B trifásico e perturbadora $>50 \mathrm{~kW}$,

- Cenário 5: Grupo B monofásico e perturbadora $<50 \mathrm{~kW}$.

Nos testes iniciais de usabilidade, verificou-se que a apresentação das cincos opções em um único card (ver Figura 4) facilitaria a usabilidade, reduzindo a obtenção da resposta do cliente a um único diálogo. No caso de escolha da Opção 5, é solicitado também a identificação de qual ou quais tipos de carga perturbadora são previstas para aquela residência. Para tanto, a solicitante deve indicar apenas o número (ou números) que aparece $(\mathrm{m})$ numa pequena lista exibida da tela do WhatsApp, por exemplo, 3 e 5 (correspondendo a motor elétrico e máquina de solda, respectivamente).

\footnotetext{
${ }^{1}$ Cargas e equipamentos potencialmente perturbadores são aqueles capazes de afetar significativamente a qualidade de tensão da rede, onerando a concessionária ou as pessoas que consomem energia. Esse tipo de carga requer a realização de estudos técnicos específicos de qualidade de energia por parte da concessionária, conforme exigido pela ANEEL.
} 


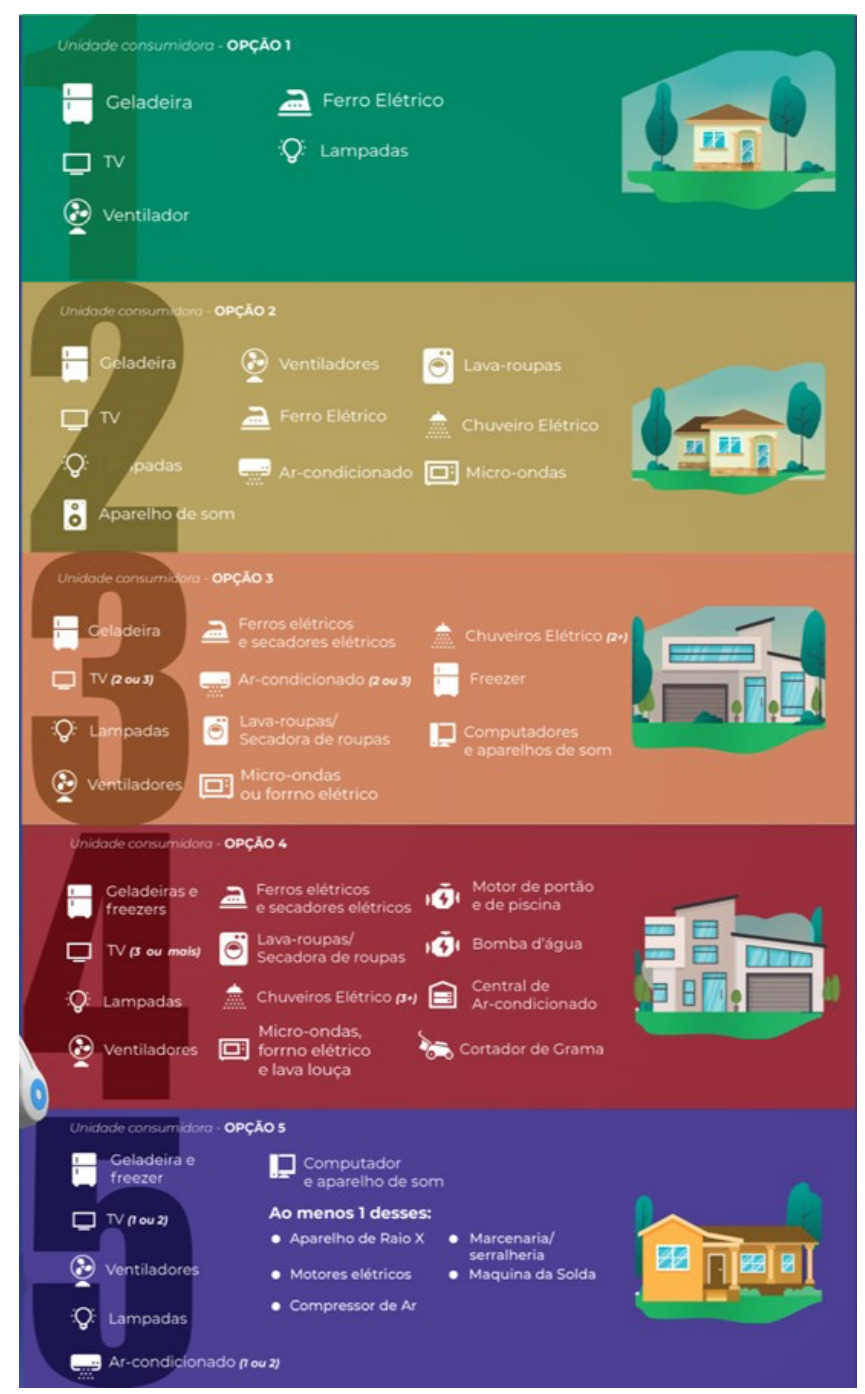

Figura 4 - Card com as 5 opções unificadas. Os atributos de acessibilidade, para leitura adequada e confortável, são ajustados com a ampliação da imagem na tela do smartphone.

Fonte: Elaborada pelos autores

Para cada opção de cenário, está associado um conjunto de características técnicas e identificação de cargas perturbadoras (bloco de carga, caso da Opção 5), que será consumido pela equipe de operações no processo de estudos de viabilidade, quando necessário, e na execução dos processos internos para provimento da conexão de energia na unidade consumidora.

\subsection{Primeiras avaliações e discussão}

No âmbito deste projeto foi desenvolvida uma ferramenta para avaliação dos aspectos de usabilidade empregados, bem como de toda a jornada de solicitação de uma ligação nova. A ferramenta baseia-se no método SUS (System Usability Scale) - ver (BROOKE, 1996) - e teve como primeira aplicação um questionário para avaliar o esforço do processo de declaração de carga. Esse método empírico mostra-se adequado por consistir em um questionário de rápida aplicação e por permitir simultaneamente a coleta de impressões subjetivas sobre a usabilidade e a satisfação do usuário (SANTANA; ALCANTRA; SIEBRA; ÁVILA, 2016). 
O questionário, implementado e disponibilizado via web, foi aplicado inicialmente entre a equipe do projeto, para efeitos de validação da ferramenta e coleta dos primeiros feedbacks sobre a implementação do protótipo da solução concebida para coleta das informações de consumo (carga) de energia elétrica, previstas para uma residência. Para cada uma das 10 questões, o colaborador deve atribuir notas de 1 a 5 , sendo o valor mais baixo corresponde a "discordo completamente" e valor mais alto, a "concordo plenamente".

Inclusive, as questões elaboradas encontram correspondência direta com algumas heurísticas de Nielsen (1994), especificamente os tópicos "Equivalência entre o sistema e o mundo real", "Consistência de padrões", "Flexibilidade", "Estética e minimalismo", e "Ajuda". Esses tópicos representam o foco principal das características de usabilidade almejadas na concepção das soluções de UX do projeto, para criar empatia e lidar com os desafios de adaptação ao canal WhatsApp e de interação com a Clara.

Apesar de as heurísticas de Nielsen serem seminais para o design de interfaces humano-máquina, algumas pesquisas têm procurado alargar essa fronteira ao buscar incluir diretrizes e heurísticas mais específicas à natureza dialógica para viabilizar desenho de recursos e avaliação de usabilidade e UX mais efetivos. Isso torna-se necessário ao se considerar a evolução constante das interfaces, sobretudo com o uso mais intenso dos agentes conversacionais (baseados tanto em texto como em fala) e os avanços dos recursos de inteligência artificial em NLP. Amershi e outros (2019), por exemplo, propõem 18 diretrizes para interação humano com IA e Langevin et al. (2021) apresentam um conjunto de heurísticas adaptadas de Nielsen e voltadas aos agentes conversacionais, com potencial de identificar questões atinentes ao desenho de interação, ao conteúdo do diálogo, privacidade de informações e até características humanizadas desses agentes. A inclusão de novas questões -inspiradas nas mencionadas por esses autores- na avaliação da usabilidade da jornada de clientes com as características técnicas e socioculturais que apontamos aqui é, inclusive, uma das linhas de trabalho futuro que identificamos como desdobramento deste projeto.

A compilação das respostas obtidas possibilita um nível de informação referente a cada tópico avaliado pela pesquisa e o valor agregado que reflete a escala SUS, conforme apresentado nas Figuras 5 e 6 . Na figura 5 , um dos tópicos avaliados (Equivalência entre o sistema e o mundo real) tem seu gráfico consolidado de respostas apresentado para ilustrar o formato de visualização das informações levantadas. Cada uma das 10 questões tem seu gráfico correspondente.

\section{Eu acho esse tipo de pergunta complicado}

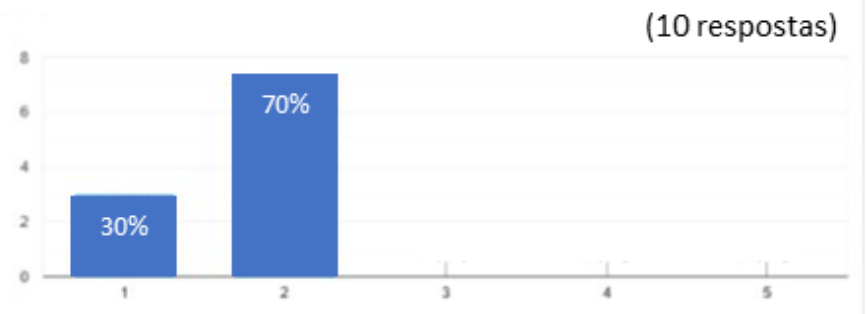

Figura 5 - Amostra do tipo de informação provido pela avaliação de usabilidade Fonte: Elaborada pelos autores

Nesse exemplo de validação, o resultado calculado para o valor da escala foi de 80,4 , segundo a metodologia SUS, enquadrando-se, portanto, no penúltimo patamar (entre 80 e 90 de um total de 100, como se pode ver na Figura 6). O estágio atual de desenvolvimento do projeto, apesar de ter entrado em sua última fase, ainda não permite avaliações mais abrangentes e contextualizadas com o conjunto completo da jornada do cliente. Como mencionado anteriormente, esses resultados não têm significância estatística, serviram apenas para validação e aperfeiçoamento da solução para declaração de carga e como preparação para os testes de campo, com usuários reais ou grupos de testes formados para este propósito. 
Avaliação da escala (Média da Rodada 1)

\begin{tabular}{|c|c|c|c|}
\hline (2) & $<60$ & Inaceitável & \multirow{3}{*}{80,4} \\
\hline$(2)$ & $60-70$ & $\mathrm{Ok}$ & \\
\hline$\Leftrightarrow$ & $70-80$ & Bom & \\
\hline (7) & $80-90$ & Excelente & \\
\hline 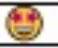 & $90-100$ & Melhor usab & \\
\hline
\end{tabular}

Figura 6 - Resultado da avaliação na escala SUS.

Fonte: Elaborada pelos autores

A recomendação, à época, era de que esses grupos realizassem a avaliação de outros recursos de usabilidade desenvolvidos no projeto e, sobretudo, avaliassem toda a jornada de quem solicita os serviços por esse canal. Para a avaliação de toda a jornada, o questionário foi ajustado para refletir a experiência integral do atendimento pela Clara, incluindo todas as etapas de formalização de seu pedido.

\section{Conclusão}

Este artigo apresentou uma síntese dos esforços de pesquisa e desenvolvimento em usabilidade e UX empreendidos no âmbito de um projeto de transformação digital para uma distribuidora de energia elétrica. $\mathrm{O}$ objetivo central desses esforços é contribuir para melhorar a experiência de uso de quem solicita uma ligação nova ou uma reativação de energia. Os princípios e métodos voltados à UX foram aplicados em pontos sensíveis e complexos da jornada dessa pessoa, como a sequência de etapas do fluxo de conversação, uma sinopse das etapas de interação humano-computador a ser apresentada no início da jornada, e o processo de declaração de carga para prever o consumo de energia da residência a ser (re)conectada. A proposição e desenvolvimento de soluções para esses pontos foi motivada por resultados de sprints de design em que se caracterizou as principais dores e necessidades da persona-chave selecionada para este projeto, assim como na experiência da equipe de atendimento a clientes, que já tem identificado pontos de dificuldade na jornada, como o processo atual de declaração de carga. Esses pontos estão também alinhados com o levantamento do estado da arte realizado sobre o tema de atendimento digital, no que pese as questões de usabilidade e o uso de multilinguagem para inclusão digital e melhoria de UX.

Nas soluções propostas para os três pontos da jornada que foram aqui apresentados, respeitou-se as características do perfil da persona identificada como foco de atenção, D. Ana, e considerou-se as condições de contorno impostas pela plataforma tecnológica existente na concessionária de distribuição de energia, pelas características de interface do canal WhatsApp e pelos recursos técnicos de comunicação que dispõe a persona-chave mencionada (como limitação de banda, indisponibilidade de wi-fi na residência, e capacidade reduzida de processamento do aparelho celular).

A sinopse da jornada, além de aplicar os mencionados princípios e métodos para melhorar a UX, é, em si, um recurso de UX design. O pré-roteiro que serviu de base para elaboração de alternativas da HQ e da animação foi implementado de forma a compor protótipos de vídeo para ideação e testes. Ambas as alternativas foram avaliadas entre os membros da equipe de projeto quanto à usabilidade e efetividade de comunicação, considerando esforço de uso, eficiência de comunicação e outros atributos específicos de UX. Com base nos resultados obtidos nessa avaliação, ainda em ambiente controlado, concluiu-se que a opção "vídeo" criou mais empatia e apresentou mais eficiência de comunicação. Em todo o caso, a narrativa adotada na construção do vídeo foi baseada na linguagem de HQ.

O processo de declaração de carga proposto foi avaliado, conforme metodologia SUS, por um grupo interno de participantes do projeto, apresentado resultados promissores. A jornada inteira de solicitação de uma ligação nova está sendo avaliada, também conforme a metodologia SUS, por uma equipe multidisciplinar da 
Equatorial, com o último release do projeto, o qual antecede sua entrada na fase operacional de campo. Ambas as avaliações são de natureza qualitativa, sem significância estatística em função do número reduzido de participantes. O próximo passo, ainda antes da entrada em operação dos serviços desenvolvidos, é proceder uma avaliação de usabilidade da jornada completa com um grupo amostral de clientes da concessionária.

Após a operacionalização dos serviços, a recomendação é que as soluções desenvolvidas e a jornada completa sejam então testadas com clientes reais em suas experiências de solicitação de serviços -garantindo base estatística, com amostras suficientes para intervalos de confiança superiores a $90 \%$. O foco dessa avaliação deverá ser nos aspectos de usabilidade, ergonomia e performance técnica, para gerar ajustes e melhorias a serem incorporadas continuamente na versão que estará em campo ou mesmo em outros serviços de atendimento via Clara.

Como desdobramentos de pesquisa, vislumbramos também a inclusão de novas heurísticas na avaliação da usabilidade da jornada digital de clientes, contemplando características técnicas e socioculturais que agreguem às heurísticas de Nielsen e possam desvelar outras dificuldades linguísticas, de uso das interfaces digitais e de interação com assistentes virtuais.

\section{Referências Bibliográficas}

ASSOCIAÇÃO BRASILEIRA DE NORMAS TÉCNICAS. NBR 9241-210: Ergonomia da interação humano-sistema - Parte 210: Projeto centrado no ser humano para sistemas interativos. Rio de Janeiro, 2011.

AMERSHI, S.; WELD, D.; VORVOREANU, M.; FOURNEY, A.; NUSHI, B.; COLLISSON, P.; SUH, J.; IQBAL, S.; BENNETT, P.N.; INKPEN, K.; TEEVAN, J.; KIKIN-GIL, R.; HORVITZ, E. Guidelines for Human-AI Interaction. Proc. of the 2019 CHI Conference on Human Factors in Computing Systems, Paper 3, p. 1-13, 2019.

BEKELE, R.; GROHER, I.; SAMETINGER, J. et al. User-Centered Design in developing countries: A case study of a sustainable intercultural healthcare platform in Ethiopia. 2019 IEEE/ACM Symposium on Software Engineering in Africa (SEiA), p. 11-15, 2019.

BRAGA, Denise Bértoli (Org.) Tecnologias digitais de informação e comunicação e participação social: possibilidades e contradições. São Paulo: Cortez, 2015.

BRAGA, Denise Bértoli. Tecnologia e participação social no processo de produção e consumo de bens culturais: novas possibilidades trazidas pelas práticas letradas digitais mediadas pela internet. Trab. Ling. Aplic., Campinas, v. 49, n.2, p. 373-391, jul./dez. 2010.

BRANDTZAEG, P. B.; FØLSTAD, A. Chatbots: Changing user needs and motivations. Interactions, v. 25, n. 5, p. 38-43, 2018.

BROOKE, John. SUS: A quick and dirty usability scale. Usability Eval. Ind. 189, p. 4-7, 1996.

CAÇADOR, A.; GANCHO, S; GOUVEIA, P. Designing for affective and ludic experiences with empathy. Proc. 10th International Conference Senses\&Sensibility '19 - Lost in (G)Localization, 2020.

CASTELLS, Manuel. A sociedade em rede. 18. ed., revista e ampliada. São Paulo: Paz e Terra, 2017.

DOPP, A.R.; PARISI, K.E.; MUNSON, S.A.; LYON, A.R. A glossary of user-centered design strategies for implementation experts. Translational Behavioral Medicine, v. 9, n. 6, p. 1057-1064, 2018. 
FINARDI, F.A.R.; HOLANDA, G.M.; ADORNI, C.Y.K.O.; NADER, M.V.P; PINHEIRO, K.R.C. Deep learning as innovation vector in the provisioning of new household electricity connections. Brazilian Journal of Development, v. 7, n. 8, p. 76112-76132, 2021.

FØLSTAD, A.; BRANDTZAEG, P. B. Chatbots and the new world of HCI. Interactions, v. 24, n. 4, p. 3842, 2017.

FOUCAULT, Michel. A ordem do discurso. 8. ed. São Paulo: Edições Loyola, 2002.

GUALTIERI, Mike. Best practices in User Experience (UX) design. Forrester Research, Inc. Sep. 4, 2009.

HE, Shushu. Design for intercultural experience: A design framework within User Experience approach. In: RAMPINO, L., MARIANI, I. (Eds.). Design Research in the digital era - Opportunities and implications. Notes on Doctoral Research in design 2020. Milano: FrancoAngeli, 2020.

HILL, J.; FORD, W. R.; FARRERAS, I.G. Real conversations with artificial intelligence: A comparison between human-human online conversations and human-chatbot conversations. Computers in Human Behavior, v. 49, p. 245-250, 2015.

HOLANDA, G.M; REZENDE, R.; SOUZA, J.M. Considerations on usability and artificial intelligence behind the pace of digital transformation. Brazilian Journal of Development, v.7. n.5, p. 47609-47624, 2021.

LANGEVIN, R.; LORDON, R.J.; AVRAHAMI, T.; COWAN, B.R.; HIRSCH, T.; HSIEH, G. Heuristic Evaluation of Conversational Agents. In: Proc. of the 2021 CHI Conference on Human Factors in Computing Systems (CHI '21), Article 632, p. 1-15, 2021.

LEMKE, Jay L. Travels in hypermodality. Visual Communication, 1 (3), p. 299-325, 2002.

MACDONALD, C.M. User Experience (UX) Capacity-Building: A conceptual model and research agenda. Proc. Designing Interactive Systems Conference - DIS'19, p. 187-200, 2019.

MAHLKE, Sascha. User experience: usability, aesthetics and emotions in human-technology interaction. In: LAW, E.; VERMEEREN, A.; HASSENZAHL, M.; BLYTHE, M. (Eds.) Towards a UX manifesto. COST294-MAUSE affiliated workshop, Lancaster, 2007.

MORVILLE, Peter. User Experience Design. Semantic Studios, June 21, 2004. Disponível em: $<$ http://semanticstudios.com/user_experience_design/ $>$. Acesso em: abril de 2021.

NIELSEN, J.; MOLICH, R. Heuristic Evaluation of User Interfaces. Proc. CHI '90. ACM, p. 249-256, 1990.

NIELSEN, Jakob. Heuristic Evaluation: usability inspection methods. New York: John Wiley \& Sons, 1994.

NORMAN, Donald A. How Might People Interact with Agents. Communications ACM, v. 37, n.7, p. 6871, 1994.

PARK, S.; HUMPHRY, J. Exclusion by design: intersections of social, digital and data exclusion. Information, Communication \& Society, v. 22, n. 7, p. 934-953, 2019. 
RIETZ T.; BENKE, I.; MAEDCHE, A. The Impact of Anthropomorphic and Functional Chatbot Design Features in Enterprise Collaboration Systems on User Acceptance. Proc. 14th International Conference on Wirtschaftsinformatik, 2019.

ROJO, R.; \& MOURA, E. Letramentos, mídias, linguagem. São Paulo: Parábola Editorial, 2019.

SANTAELLA, Lucia. Culturas e artes do pós-humano: da cultura das mídias à cibercultura. São Paulo: Paulus, 2003.

SANTANA, C.A.; ALCANTRA, R.A.; SIEBRA, S. A.; ÁVILA B.T. Comparando Métodos de Avaliações de Usabilidade, de Encontrabilidade e Experiência do Usuário. Informação \& Tecnologia (ITEC), v.3, n.1, p. 83-101, 2016.

SPRINGETT, M.; FRENCH, T. User experience and its relationship to usability - The case of e-commerce web-site design. . In: LAW, E.; VERMEEREN, A.; HASSENZAHL, M.; BLYTHE, M. (Eds.) Towards a UX manifesto. COST294-MAUSE affiliated workshop, Lancaster, 2007.

VREDENBURG, K.; MAO, J.-Y.; SMITH, P. W.; CAREY, T. A survey of user-centered design practice. Proc. of the SIGCHI Conference on Human Factors in Computing Systems (CHI '02), v. 4, n. 1, p. 471478, 2002.

\section{Agradecimentos}

Os autores agradecem a ANEEL (Agência Nacional de Energia Elétrica) cujo programa de Pesquisa \& Desenvolvimento viabilizou a realização deste trabalho, bem como ao time de pesquisadores e técnicos envolvidos no projeto, especialmente Aline F. Vasconcelos e Grabriela S. S. Cestari, pelos cuidados com a voz, fala e imagem da Clara. Agradecem também as oportunas contribuições dos revisores para este artigo. 